\title{
Realization of Music Fountain Control system based on single Chip Microcomputer
}

\author{
Biqing $\mathrm{Li}^{1}$, Zhao $\mathrm{Li}^{2}$, a), Suping Jiang ${ }^{3, \text { b) }}$ \\ ${ }^{1}$ School of Information and Communication Engineering, Hezhou University, Hezhou Guangxi 542899, China; \\ ${ }^{2}$ Management Engineering Department, Guangxi Vocational and Technical College of Communications, Nanning \\ Guangxi 545000, China; \\ ${ }^{3}$ Guangxi Talent International College, Qinzhou Guangxi 535000, China; \\ a)229292710@qq.com \\ b) Corresponding author: janliful@163.com,
}

\begin{abstract}
With the development of society, people's living standards improve, on the side of entertainment have become increasingly demanding, musical fountain as a highly ornamental recreational facilities, increasing the public's favorite subject. According to the current development of musical fountain, this design uses STC89C52 microcontroller, AD capture chip, power amplifier chip, motors and other components made of musical fountain system.
\end{abstract}

Key words: music fountain; SCM; STC89C52, Acquisition chip.

\section{INTRODUCTION}

\section{Subject Background}

Musical fountain is a kind of very ornamental entertainment facility. As people's living standards improve, musical fountains are more and more popular, and various kinds of musical fountains are created. According to the differences of geographical location of different cities and cultural custom, musical fountains are designed to produce diverse effects of three-dimension. These different effects are generated due to that the sound waves, light waves or laser light pass through the water molecules. Therefore, during the performance of the fountain, the water flow generated by the fountain will be controlled by the system set in advance, and by light refraction and scattering, finally forming a threedimensional solid picture.

\section{GENERAL DESIGN}

STC89C52 CSM is the main functional chip of the designing system. The chip mainly has two functions. One is to collect the collected music signal. Another is to control the motor rotation speed according to the size of the collected music signal. The height of water columns from the pump are also different according to the changes of rotation speed. The number of 8 LED red lantern lights on or off, is also controlled by the STC89C52 CSM according to the strength degree of the music signal.

\section{AUDIO AMPLIFIER CIRCUIT DESIGN}

The musical fountain designed here uses an external audio source and the amplitude of such external music signals is generally weak. As a result, it's necessary to limit amplification of the collected audio source signal, after such 
treatment it can be sent into the A / D converter. The musical fountain's designing uses the LM386 chip as the audio amplifier circuit chip. The LM386 is a commonly used audio power amplifier produced by a company in the United States. The LM386 is mainly used in low-voltage consuming products due to its low power consumption, wide operating voltage range and relatively fewer other accessory components. As a commonly used audio amplifier, LM386 is often used in electronic designing works. It is consisted of 10 transistors which form input stage, voltage gain and current-driven stage.

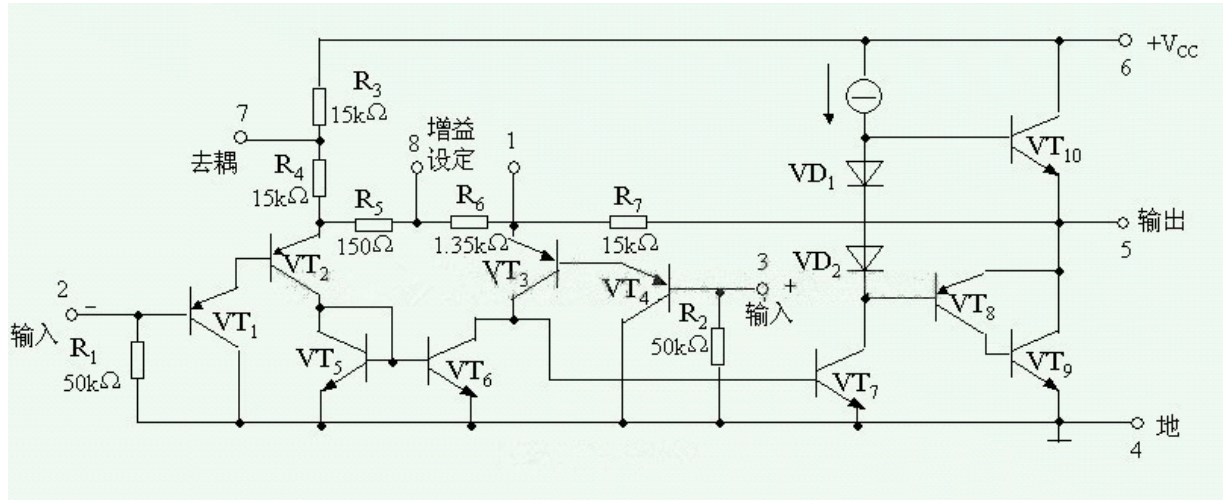

FIGURE 1. LM386Internal schematic diagram

\section{STC89C52}

This design uses STC89C52 as the main chip. The STC89C52 is a low-power, high-performance CMOS 8-bit micro-controller manufactured by STC. It has 8K in system programmable Flash memory. The STC89C52 uses the classic MCS-51 core. But a lot of improvements made on the chip make it more functional than traditional 51 microcontroller. On a single chip,it has a flexible 8-bit CPU and system programmable Flash, which makes the STC89C52 have the possibility to provide a highly flexible and efficient solution for a wide range of embedded control application systems. The chip has the following standard features: 8k bytes Flash, 512 bytes RAM, 32-bit I / O port, watchdog timer, built-in 4KB EEPROM, MAX810 reset circuit, three 16-bit timers / counters, four external interruption devices, a 7-vector 4-level interruption structure(compatible with the traditional 51 5-vector 2-level interruption structure)and full duplex serial port[4]. Besides, the data retention time of STC89C52 CSM is up to 10 years, using high-density non-volatile memory technology to manufacture, is ideal to use in the design of the work. Therefore, the system's main controller uses this solution. Figure 5 is the pin diagram of STC89C52 chip.

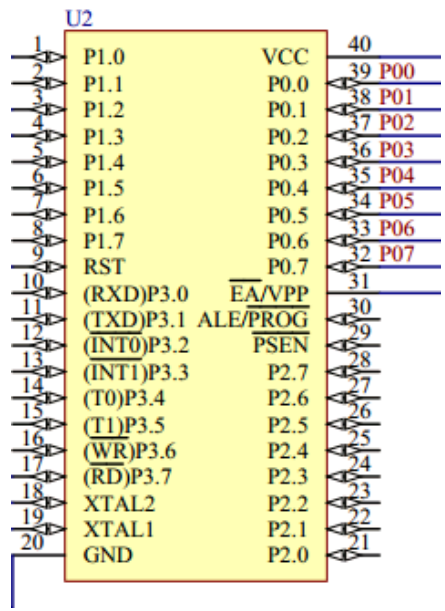

FIGURE 2. STC89C52 chip 


\section{The connection of ADC0832 and $89 \mathrm{C52}$ CSM}

The clock signal of ADC0832 comes from ALE signal of CSM STC89C52. STC89C52 adopts 24MHz clock frequency while ALE adopts $2 \mathrm{MHz}$ which after being divided by four is $500 \mathrm{kHz}$ used as ADC0832's clock frequency. P1.3 is used to control the start of A / D conversion and read out the digital quantity after the completion of conversion. The address latch of ADC0832 enables pin (ALE) H and start pin (START) to connect. The signal provided by P1.3 and WR signal through NOR gate will send the 3-channel address provided by P1.0, P1.2 and P1.3 to ADC0832 for latching to select the channel number. The conversion end signal EOC is used as the inquiry signal. Specific interface circuit shown in Figure 7:

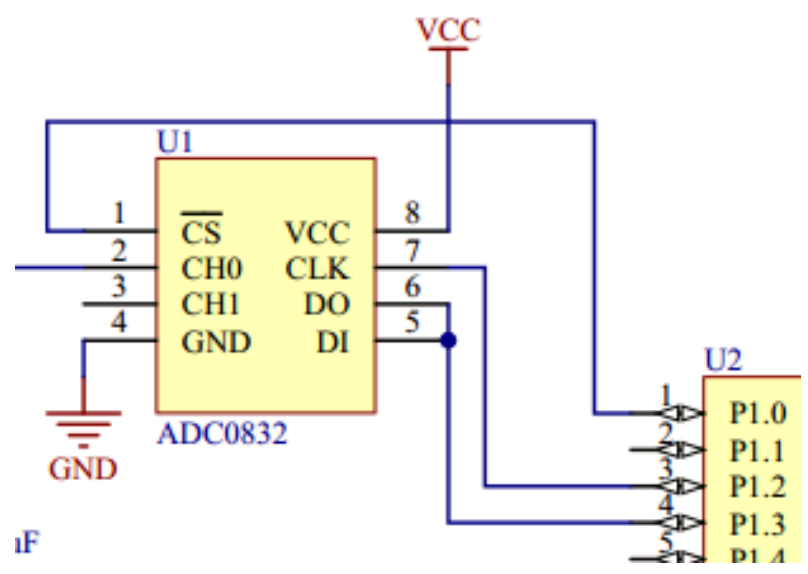

FIGURE 3. The connection of ADC0832and 89C52 CSM

Problems encountered in the process of debugging and solutions

The schematic the design is based on Prote199se software to draw and create pictures, and finally forms PCB graphics. At first, due to the circuit diagram of the schematic has no connection errors, resulting in PCB layout occurred in many places where a lot of the connections are not in place. Later, by checking for errors and reconnecting where unconnected well, it comes to the correct PCB map.

Then according to the schematic diagram and PCB map, the work was accomplished. When I did the work testing, I found that it did not work. Initially I thought that somewhere of the circuits was short, so I used a multimeter to check the circuits section by section. When all of the circuits were detected, I found no problem with the circuit. Then I began to check the component pin and the circuit link to make sure if it was caused by welding problems the component. I used electric iron and solder to re-weld the pins of the components one by one. After the job was done, I found that the work could work. Although I do not know which one or some of the components was not soldered, I am glad to see that the work was produced successfully. Although I do not know which one or some of the components are not soldered, I am glad to see that the work was produced successfully.

Although many problems arose during the design of the work, after careful examination and revision, they all had been solved and finally the work of design was made.

A part of code as follow:

\#include $<$ reg51.h>

\#define uchar unsigned char

\#define uint unsigned int

sbit out $=\mathrm{P} 3^{\wedge} 7$;

sbit led $1=\mathrm{P} 0^{\wedge} 0$;

sbit led $2=\mathrm{P} 0 \wedge$ 1 ;

sbit led $3=\mathrm{P} 0 \wedge 2$;

sbit led $4=\mathrm{P} 0 \wedge 3$;

sbit led $5=\mathrm{P} 0 \wedge 4$

sbit led6 $=\mathrm{P} 0 \wedge 5$;

sbit led $7=\mathrm{P} 0 \wedge 6$; 
sbit led $8=\mathrm{P}^{\wedge} 7$;

sbit $\mathrm{SCL}=\mathrm{P} 1 \wedge 2$;

sbit $\mathrm{DO}=\mathrm{P} 1^{\wedge} 3$;

sbit $\mathrm{CS}=\mathrm{P} 1^{\wedge} 0$;

uchar h1, date;

unsigned char adval;

void delay (uint $\mathrm{z}$ )

\{

uchar y;

for $(; \mathrm{z}>0 ; \mathrm{z-}-)$

for $(\mathrm{y}=5 ; \mathrm{y}>0 ; \mathrm{y}--)$;

\}

unsigned char ad0832read (bit SGL, bit ODD)

\{

unsigned char $\mathrm{i}=0$, value $=0$, value $1=0$;

$\mathrm{SCL}=0$;

$\mathrm{DO}=1$;

$\mathrm{CS}=0$;

$\mathrm{SCL}=1$;

$\mathrm{SCL}=0$;

$\mathrm{DO}=\mathrm{SGL}$;

$\mathrm{SCL}=1$;

$\mathrm{SCL}=0$;

$\mathrm{DO}=\mathrm{ODD}$;

$\mathrm{SCL}=1$;

$\mathrm{SCL}=0$;

$\mathrm{DO}=1$;

for $(\mathrm{i}=0 ; \mathrm{i}<8 ; \mathrm{i}++)$

\{

$\mathrm{SCL}=1$;

$\mathrm{SCL}=0$;

value $<<=1$;

if(DO)

value++;

\}

for $(\mathrm{i}=0 ; \mathrm{i}<8 ; \mathrm{i}++)$

\{

value $1<<=1$;

if(DO)

value $1+=0 \times 80$;

$\mathrm{SCL}=1$;

$\mathrm{SCL}=0$;

\}

$\mathrm{CS}=1$;

$\mathrm{SCL}=1$;

if(value $==$ value 1 )

return value;

return 0 ;

\}

void penquan()

\{

date $=\operatorname{ad0832} \operatorname{read}(1,0)$;

h1=(255-date);

out $=1$; 

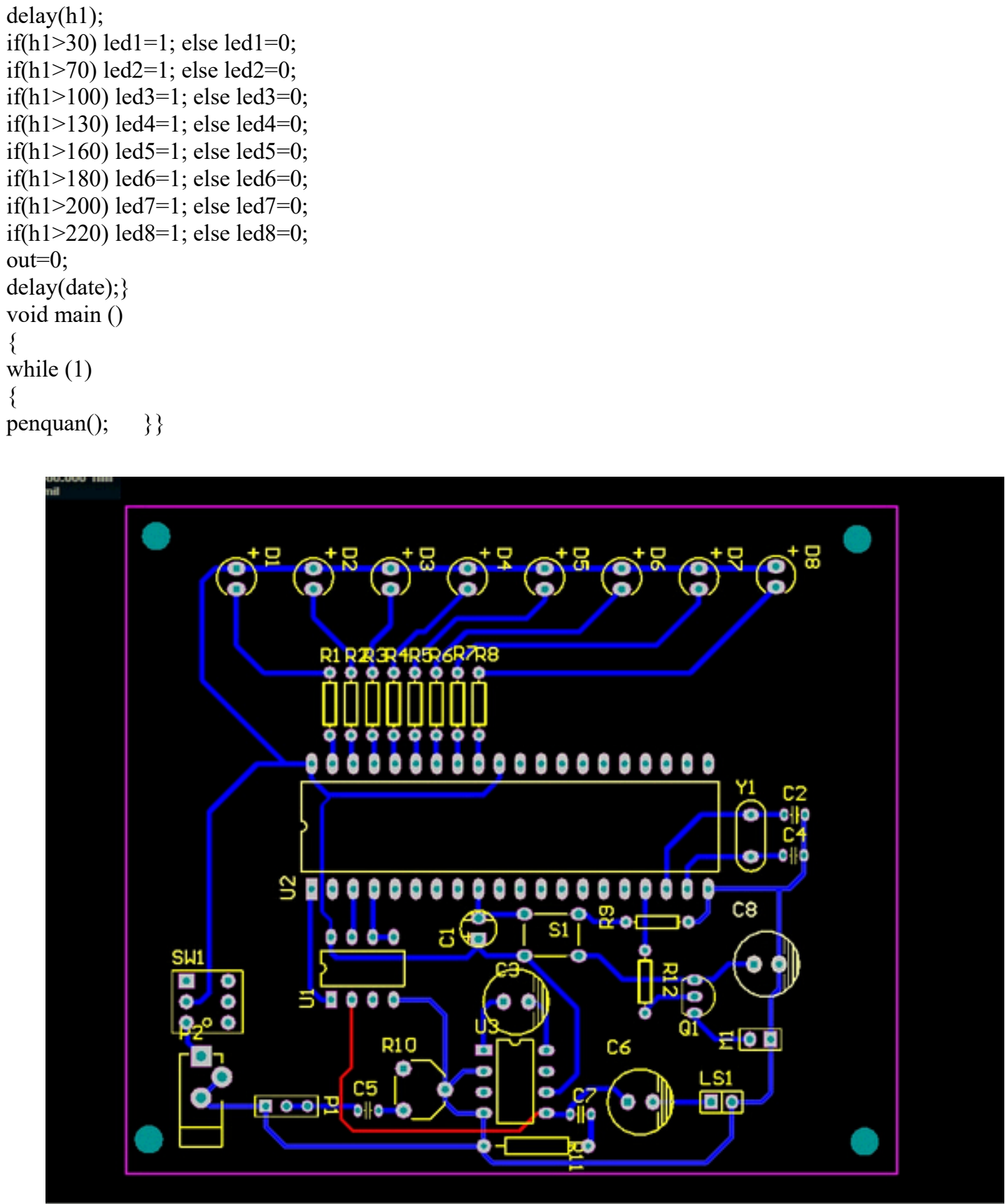

\section{SUMMARY}

In the design process, I found a lot of my shortcomings. The knowledge learned in the past is only a drop in the ocean.For which at the very beginning of my design, I felt hopeless and knew nothing about how to complete the graduation project, unable to start it. Later through searching information on the Internet and reading literature, step by step I got an understanding of structure and production principle of "musical fountain", carefully figured out the functions of of the various chips needed in the process of making musical fountain as well as the role of various subcircuits. Through continuous failure and correction, ultimately, I completed the design of "musical fountain control system based on CSM". 


\section{ACKNOWLEDGEMENTS}

This work is supported the following fund:

2017 The student work subject program of Hezhou university:"college students' network addiction of the student work service research"(No,hzxysz201707).

2016 The project of improving the basic ability of young teachers in Colleges and universities in Guangxi:"An empirical study of Guangxi Beibu Gulf Economic Zone Foreign Trade Company foreign trade English correspondence" (No, KY2016YB886).

2016 The higher education research subject project project of Hezhou university:"between collaborative innovation research of entrepreneurial talent cultivation system".

2017 college students' innovative entrepreneurial project:'The agricultural robot autonomous operations research based on machine vision"(No,201711838096) \&\&"Multi-functional autonomous agriculture robot development" (No,201711838121) \&\&"Research and development of navigation system for agricultural robot'(No,201711838008) $\& \&$ "Research and development of data acquisition system and servo control system for mobile platform of agricultural robot" (No,201711838075) \&\&"Research and development of visual navigation system for agricultural robot test platform"(No,201711838076).

2017 Guangxi education science 'ten-three-five' planning project:'Based on zte's ICT education platform of fusion, work-integrated learning education training mode research"(No,2017B107).

\section{REFERENCES}

1. B.Q LI, Y.F LING, H.Y ZHANG, S.Y ZHENG: The Design and Realization of Cherry Tomato Harvesting Robot Based on IOT. International Journal of Online Engineering, 12(12), 23, (2016).

2. B.Q LI, W.L GUAN, S.Y ZHENG, X.G Yue: OPTIMISATION DESIGN OF CORN PRECISION SEEDER BASED ON MULTI-ROUTE AND MULTI-CHANNEL CONTROL. JOURNAL OF THE BALKAN TRIBOLOGICAL ASSOCIATION, 21(4A), 1215, (2015).

3. B.Q LI, X.M YANG GUAN, S.Y ZHENG: Internet of Things-based Simulation Study on Lijiang River Water Environment Monitoring. Journal of Coastal Research,79, 1-5, (2017).

4. B.Q Li, et al, Intelligent Control Management System and Its Application, in: PROCEEDINGS OF THE 2016 INTERNATIONAL CONFERENCE ON ECONOMICS AND MANAGEMENT INNOVATIONS, Wuhan, China, 2016, PP.68-71.

5. B.Q Li, et al, Design and Implementation of Tanks War Game Based on the Android Platform, in: PROCEEDINGS OF THE 2016 2ND WROKSHOP ON ADVANCED RESEARCH AND TECHNOLOGY IN INDUSTRY APPLICATIONS, Dalian, China, 2016, PP.963-966.

6. B.Q Li, et al, Design of a Tea Garden Antifreezing Control System, in: PROCEEDINGS OF THE 2016 6TH INTERNATIONAL CONFERENCE ON MACHINERY, MATERIALS, ENVIRONMENT, BIOTECHNOLOGY AND COMPUTER(MMEBC), Tianjin, China, 2016, PP.736-738.

7. B.Q Li, et al, Design of Electronic Compass, in: PROCEEDINGS OF THE 2016 6TH INTERNATIONAL CONFERENCE ON MACHINERY, MATERIALS, ENVIRONMENT, BIOTECHNOLOGY AND COMPUTER (MMEBC), Tianjin, China, 2016, PP.1240-1243.

8. B.Q Li, et al, Research of Automatically Light-Adjusting Lamp, in: PROCEEDINGS OF THE 2016 INTERNATIONAL CONFERENCE ON COMPUTER ENGINEERING, INFORMATION SCIENCE \& APPLICATION TECHNOLOGY (ICCIA 2016), Guilin, China, 2016, PP.249-252.

9. B.Q Li, et al, The Design and Realization of Fruit Harvesting Robot Based on IOT, in: PROCEEDINGS OF THE 2016 INTERNATIONAL CONFERENCE ON COMPUTER ENGINEERING, INFORMATION SCIENCE \& APPLICATION TECHNOLOGY (ICCIA 2016), Guilin, China, 2016, PP.261-264.

10. B.Q Li, et al, A New Type of Automatic Opening and Closing Light-Operated Curtain, in: PROCEEDINGS OF THE 2016 INTERNATIONAL CONFERENCE ON MECHATRONICS ENGINEERING AND INFORMATION TECHNOLOGY(ICMEIT), Xian, China, 2016, PP.66-69.

11. B.Q Li, et al, Design of the Intelligent Air Humidifier, in: PROCEEDINGS OF THE 2016 INTERNATIONAL CONFERENCE ON MECHATRONICS ENGINEERING AND INFORMATION TECHNOLOGY(ICMEIT), Xian, China, 2016, PP.201-203. 
12. B.Q Li, et al, The Design Implementation of the APP of Experiencing Guangxi Folk Custom, in: PROCEEDINGS OF THE 2016 INTERNATIONAL CONFERENCE ON ECONOMICS AND MANAGEMENT INNOVATIONS, Wuhan, China, 2016, PP.47-50.

13. S.Y Zheng, et al, Digital Display Design of Ethnic Clothing of Nanling, in: PROCEEDINGS OF THE 4TH INTERNATIONAL CONFERENCE ON MECHATRONICS,MATERIALS.CHEMISTRY AND COMPUTER ENGINEERING 2015(ICMMCCE 2015), Xian, China, 2015, PP.2805-2808.

14. Java, in: PROCEEDINGS OF THE 2015 INTERNATIONAL CONFERENCE ON EDEDUC ATION, MANAGEMENT AND COMPUTING TECHNOLOGY(ICEMCT-16), Hangzhou, China, 2016, PP.957-960.

15. S.Y Zheng, et al, Brief analysis on"HeYuanTong”Campus Mobile Phone APP Design, in: PROCEEDINGS OF THE 2015 5TH INTERNATIONAL CONFERENCE ON COMPUTER SCIENCES AND AUTOMATION ENGINEERING, Sanya, China, 2015, PP.151-154.

16. S.Y Zheng, et al, Social Work in Teen Addiction Correction Services Research Under the New Situation, in: PROCEEDINGS OF THE 2015 4TH NATIONAL CONFERENCE ON ELECTRICAL, ELECTRONICS AND COMPUTER ENGINEEERING (NCEECE 2015), Xian, China, 2015, PP.252-255.

17. B.Q Li, et al, The Design of Remote Temperature Monitoring System, in:International Conference on Green Energy and Sustainable Development, MAY 27-28, 2017, PP.20-22.

18. B.Q Li, et al, Design of Portable Valuables Touch Alarm Circuit,in:International Conference on Advances in Materials, Machinery, Electronics ,2017, PP.27-32.

19. B.Q Li, et al, Design and Implementation of a Simple Acousto Optic Dual Control Circuit, in:5th International Conference on Computer-Aided Design, Manufacturing, Modeling and Simulation,2017, PP.78-80.

20. B.Q Li, et al, Design of electronic lock based on single-chip microcomputer, in:4th International Conference on Electrical and Electronics Engineering and Computer Science ,2017, PP.55-60.

21. B.Q Li, et al, The Design of Chicken House Electronic Intelligent Lighting Apparatus,in:International Conference on Mechanical, Electronic, Control and Automation Engineering,2017, PP.15-20.

22. B.Q Li, et al, Office Automation Sub-Summary of the Work and the Project Management System,in:International Conference on Mechanical, Electronic, Control and Automation Engineering,2017, PP.46-48.

23. B.Q Li, et al, The Design of Intelligent Heat Dissipator Control Circuit,in:PROCEEDINGS OF THE 2017 2ND INTERNATIONAL CONFERENCE ON MATERIALS SCIENCE, MACHINERY AND ENERGY ENGINEERING,2017, PP.22-25.

24. B.Q Li, et al, The Design of IPv6's Transitional Scheme in University,in:International Conference on Materials Science, Energy Technology, Power Engineering (MEP) ,2017, PP.91-93.

25. B.Q Li, et al, The Personal Receiving Document Management and the Realization of Email Function in OAS,in:International Conference on Materials Science, Energy Technology, Power Engineering (MEP) ,2017, PP.121-123.

26. S.Y Zheng, et al, Design and Implementation of an Audio Indicator,in: 5th International Conference on Computer-Aided Design, Manufacturing, Modeling and Simulation,2017, PP.21-23.

27. S.Y Zheng, et al, Implementation and Application of ACL in Campus Network, in: International Conference on Advances in Materials, Machinery, Electronics ,2017, PP.151-153.

28. S.Y Zheng, et al, The Design of Liquid Drip Speed Monitoring Device System Based on MCU,in:International Conference on Green Energy and Sustainable Development, MAY 27-28, 2017, PP.51-53.

29. S.Y Zheng, et al, The Design of Hearing and hypnosis all-in-one Machine, in:International Conference on Mechanical, Electronic, Control and Automation Engineering,2017, PP.66-68.

30. S.Y Zheng, et al, Campus Network Security Defense Strategy,in:International Conference on Mechanical, Electronic, Control and Automation Engineering,2017, PP.30-33.

31. S.Y Zheng, et al, Design and implementation of multifunctional charger,in:International Conference on Materials Science, Energy Technology, Power Engineering (MEP) ,2017, PP.71-73. 